\title{
PRÉ-ESFRIAMENTO PARA SUPERAÇÃO DA DORMÊNCIA DE SEMENTES DE TRIGO COLHIDAS NA ÉPOCA DA MATURIDADE ${ }^{1}$
}

\author{
FRANCISCO DE ASSIS FRANCO ${ }^{2}$, RONALD JOSÉ BARTH PINTO ${ }^{3}$, CARLOS ALBERTO SCAPIM ${ }^{3}$, \\ IVAN SCHUSTER ${ }^{2}$, JOSELAINE VIGANO ${ }^{4}$, VOLMIR SERGIO MARCHIORO² \\ ALESSANDRO DE LUCCA E BRACCINI ${ }^{3}$
}

\begin{abstract}
RESUMO -O melhoramento genético de trigo tem gerado número expressivo de cultivares que diferem quanto ao potencial de germinação de sementes ainda presas à espiga. Para avaliar essas diferenças, foi conduzida pesquisa com sementes colhidas em dois locais, Palotina e Cascavel, Estado do Paraná, incluindo doze cultivares em delineamento blocos casualizados, com quatro repetições. As sementes foram colhidas na época da maturidade fisiológica, sendo uma das amostras submetida a pré-esfriamento para superação da dormência e a outra representou a testemunha não tratada. As sementes que não germinaram foram submetidas ao teste de tetrazólio para confirmar a ocorrência de dormência. Os resultados foram submetidos a análise da variância e à posterior determinação da significância da diferença entre médias. A análise dos resultados permitiu verificar que, nas duas localidades, os percentuais de germinação de sementes de 'Frontana' e de 'IAPAR 53', foram extremamente baixos, indicando a existência de maior número de sementes dormentes. $\mathrm{O}$ método de superação de dormência para amostras provenientes de Palotina não foi eficiente para permitir a completa germinação das sementes. Por outro lado, o resfriamento de amostras colhidas em Cascavel permitiu a germinação das sementes de todas as cultivares. A manifestação da dormência, detectada em 'Frontana' e em 'IAPAR 53', é considerada eficiente para impedir a germinação indesejável das sementes ainda presas à espiga, na época da maturidade fisiológica.
\end{abstract}

Termos para indexação: Triticum aestivum, fisiologia de semente, germinação, tetrazólio.

\section{PRECHILING AS A TREATMENT TO OVERCOME DORMANCY OF WHEAT SEEDS HARVESTED AT PHYSIOLOGICAL MATURITY}

\begin{abstract}
The wheat breeding program has generated an expressive number of cultivars which differ in sprouting rate of seed still attached to the spike. In order to assess these differences, an experiment was carried out with seeds harvested from two locations, Palotina and Cascavel, in Paraná State, Brazil, consisting of twelve cultivars in a randomized block design with four replications. Seeds were harvested at physiological maturity, in which one sample was submitted to a pre-chilling
\end{abstract}

${ }^{1}$ Submetido em 15/09/2008. Aceito em 02/02/2009.

${ }^{2}$ Eng. Agr., Dr., Pesquisador da Cooperativa Central de Pesquisa Agrícola (COODETEC), BR 467, km 98, Caixa Postal 301, 85813-450, Cascavel, PR; e-mail: franco@coodetec.com.br; ivan@coodetec.com.br; volmir@ coodetec.com.br

${ }^{3}$ Eng. Agr., Dr., Professor Associado do Departamento de Agronomia da
Universidade Estadual de Maringá (UEM), Av. Colombo, 5790, Bloco J-45, 87020-900, Maringá, PR; e-mail: rjbpinto@uem.br; cascapim@uem. br; albraccini@uem.br

${ }^{4}$ Bióloga, M.Sc., Estudante do Programa de Pós-Graduação em Genética e Melhoramento da UEM, Maringá, PR; e-mail: josyvigano@yahoo.com.br 
period to overcome seed dormancy, while the other was untreated (control). Seeds which did not germinate were submitted to the tetrazolium test to detect dormancy occurrence. Results showed that in both locations the germination percentage of 'Frontana' and 'IAPAR 53' seeds was extremely low, indicating the presence of a significant number of dormant seeds. The method to overcome dormancy from the Palotina samples was not efficient to result in a complete seed germination. On the other hand, pre-chilling of samples harvested in Cascavel resulted in complete seed germination. The dormancy phenomenon detected in both 'Frontana' and 'IAPAR 53' seeds seemed to be efficient in preventing germination of seeds still attached to the spike at physiological maturity.

Index terms: Triticum aestivum, seed physiology, germination, tetrazolium.

\section{INTRODUÇÃO}

O problema de germinação na pré-colheita em trigo atinge áreas de várias partes de regiões produtoras no mundo, principalmente, Norte e Oeste da Europa, Noroeste dos Estados Unidos da América, Norte da Austrália, Oeste da Nova Zelândia, Canadá, África do Sul, Chile, Argentina e Brasil (Cunha et al., 2004). Na Austrália, onde se produz somente trigo branco, por possibilitar a extração de uma maior quantidade de farinha, ocorrem grandes perdas por germinação na época pré-colheita (Derera, 1980; Flintham, 2000). No Reino Unido, a germinação das sementes ainda presas à espiga, sob condições climáticas adversas, durante o período de maturação é uma das fontes de danos em culturas comerciais de trigo (Lunn et al., 2001). Bassoi (2004) ressaltou que, em regiões marítimas com verão chuvoso e em regiões subtropicais, onde o trigo de primavera é cultivado durante o inverno, como em algumas partes do Brasil, existe alta probabilidade da ocorrência de germinação dos grãos na época pré-colheita.

As condições de ambiente nas regiões de cultivo de trigo, no Brasil, favorecem a ocorrência de chuvas na época da colheita (Bassoi, 2002; Cunha et al., 2004). Por isso, podem causar perda acentuada de germinação e de qualidade industrial, para a maior parte das cultivares. Desta forma, muitas áreas destinadas à produção de sementes são inviabilizadas, pois, em decorrência da alta atividade de alfa-amilase, enzima produzida durante o desencadeamento do processo germinativo, os produtos gerados têm pouca ou nenhuma possibilidade de utilização pela indústria de alimentos.

A antecipação da colheita pode representar uma estratégia interessante para a redução no risco de germinação das sementes ainda presas à espiga. Para Carvalho e Nakagawa (2000), a colheita deve ser realizada quando as sementes atingem a maturidade fisiológica, isto é, quando se desligam da planta mãe, ponto a partir do qual ocorre rápida desidratação. Contudo, a colheita nesse momento é impraticável, pois as plantas ainda apresentam quantidade relativamente grande de partes de colmos, nós e ráquis, com alto grau de umidade. Nessa situação, o elevado teor de água dificulta a colheita e aumenta a probabilidade da ocorrência de injúrias mecânicas às sementes.

A tolerância à germinação na fase pré-colheita é dependente da base genética da cultivar, das condições de colheita, secagem e armazenamento, da região de cultivo e das interações das cultivares com o ambiente (Hagemann e Ciha, 1987; King, 1993; Simpson, 1990; Kigel e Galili, 1995; Taiz e Zeiger, 2000; Castro et al., 2004). Essa tolerância está relacionada a características que determinam a morfologia das espigas, sensibilidade hormonal e inibidores de alfaamilase (Barnard et al., 2005).

Sementes recém-colhidas, ainda úmidas, apresentam capacidade de germinação inferior submetidas à secagem prévia, provavelmente por ocorrerem processos essenciais à germinação durante o período de perda de água (Bewley e Black, 1985). Khan (1971) atribuiu às citocininas o equilíbrio hormonal, com a função de anular o efeito dos inibidores, permitindo às giberelinas exercerem efeitos estimuladores. Em cereais, observa-se a presença de proteínas inibidoras de alfa-amilase, sendo ativas principalmente contra enzimas endógenas, para evitar a degradação precoce e inapropriada das reservas de amido (Simpson, 1990; Kigel e Galili, 1995). A indução da síntese de enzimas alfa-amilase está relacionada 
principalmente com a disponibilidade do ácido giberélico (GA), produzido pelo eixo embrionário e difundido até o escutelo e a camada de aleurona, onde atua como ativador primário (Kigel e Galili, 1995; Taiz e Zeiger, 2000; Castro et al., 2004).

A temperatura é um fator com influência significativa na expressão da dormência em sementes de trigo, durante o período de enchimento dos grãos e após a maturidade. Em trabalho desenvolvido para avaliação da dormência, Belderock (1976) encontrou correlação positiva entre a intensidade de dormência e a temperatura durante a maturação ou após a maturidade. A dormência das sementes é induzida pela baixa temperatura, durante o período de enchimento das sementes, porém a baixa temperatura também é efetiva para superar a dormência após a maturidade (Reddy et al., 1985). A expressão da dormência ocorre quando sementes maduras e sadias não germinam, quando expostas a condições aparentemente adequadas de umidade, temperatura, luz e oxigênio (Bewley e Black, 1985; Popinigis, 1985; Hilhorst, 1995; Carvalho e Nakagawa, 2000; Castro et al., 2004).

Segundo Castro et al. (2004), a quebra da dormência está relacionada a fatores internos e externos à semente. Popinigs (1985) indicou vários métodos para superar a dormência de sementes de gramíneas. Os principais são a ruptura da cariopse, o tratamento com nitrato de potássio, exposição à luz, o emprego de temperaturas alternadas, o pré-esfriamento, tratamento com hormônios (geralmente giberilinas, citocininas e etileno). Entre os reguladores de crescimento, as giberelinas (geralmente o ácido giberélico, $\mathrm{GA}_{3}$, mas também $\mathrm{GA}_{4}$ e GA 7 ), as citocininas (principalmente a cinetina e a leuziladenina) e o etileno são os compostos citados como os mais relacionados à quebra de dormência (Carvalho e Nakagawa, 2000).

A resistência à germinação foi demonstrada por Flintham e Gale (1996), em testes para verificação da intensidade de dormência em linhas isogênicas de trigo de grãos vermelhos e brancos. O principal componente da variação genética da germinação na pré-colheita de trigo parece ser o grau de dormência, que necessita ser avaliado como mecanismo de possível transferência para outros cultivares (Flintham, 2000; Bassoi, 2002; Miura et al., 2002; Osa et al., 2003). Assim, a identificação de cultivares tolerantes à germinação na espiga pode ser uma importante ferramenta na seleção de genótipos para os programas de melhoramento genético em trigo.

Diante do exposto, objetivo desse experimento foi caracterizar a presença de dormência e as diferenças na expressão de germinação em cultivares nacionais de trigo em duas localidades do estado do Paraná.

\section{MATERIAL E MÉTODOS}

A pesquisa foi conduzida com sementes de doze cultivares de trigo (BRS 177, BRS 208, BRS 210, CD 104, CD 105, CD 108, Frontana, IAPAR 53, IPR 85, OCEPAR 18, Ônix e BRS 18-Terena), recomendadas para o estado do Paraná. O primeiro experimento foi semeado em 22/04/2005, no Centro de Pesquisa da Coodetec, em Palotina, estado do Paraná (latitude: 24 17' 02'; altitude: $333 \mathrm{~m}$ ) e, o segundo, instalado em 14/05 do mesmo ano, no Centro de Pesquisa da Coodetec, em Cascavel, estado do Paraná (latitude: $24^{\circ} 47^{\prime} 21^{\prime \prime}$; altitude: $781 \mathrm{~m}$ ). Ambos os experimentos foram delineados em blocos completos casualizados, com quatro repetições. O controle de doenças durante o desenvolvimento das plantas, quando necessário, foi efetuado conforme as recomendações técnicas para a cultura do trigo (Iapar, 2003). As plantas foram colhidas quando atingiram a maturidade fisiológica, isto é, quando as espigas estavam amareladas, mas os nós dos colmos ainda se mantinham verdes (Hanft e Wych, 1982). Foram colhidas 50 espigas por parcela. Tais espigas foram secadas sob temperatura ambiente, em um telado coberto, durante 20 dias, até atingirem aproximadamente 13\% de água.

Os dados climáticos de temperaturas mínima, média e máxima $\left({ }^{\circ} \mathrm{C}\right)$, umidade relativa $(\%)$ e precipitação pluvial $(\mathrm{mm})$, durante o período de enchimento de grãos, nas duas localidades, foram registrados e encontram-se nas Figuras 1 e 2 .

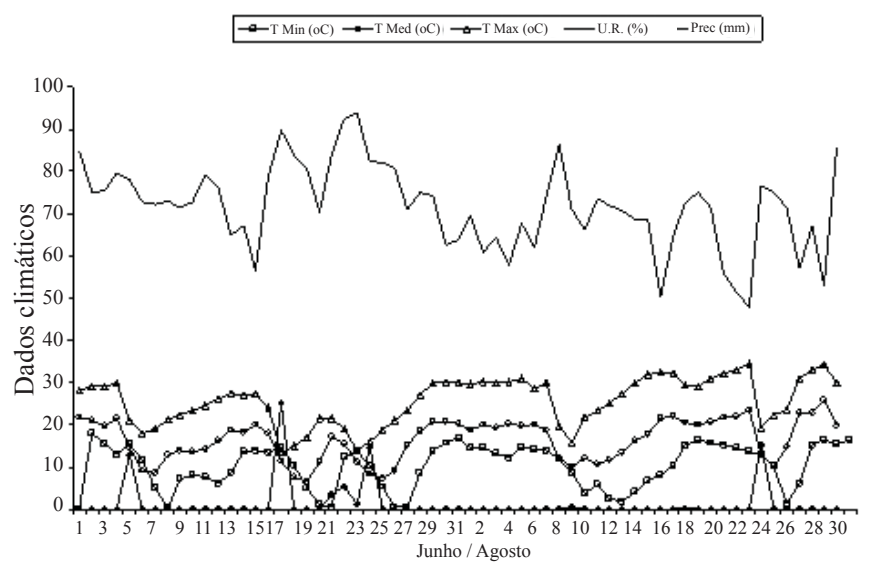

FIGURA 1. Dados de temperatura mínima, média e máxima $\left({ }^{\circ} \mathrm{C}\right)$, umidade relativa $(\%)$ e precipitação $(\mathrm{mm})$, nos meses de formação de sementes julho e agosto em Palotina, 2005. 


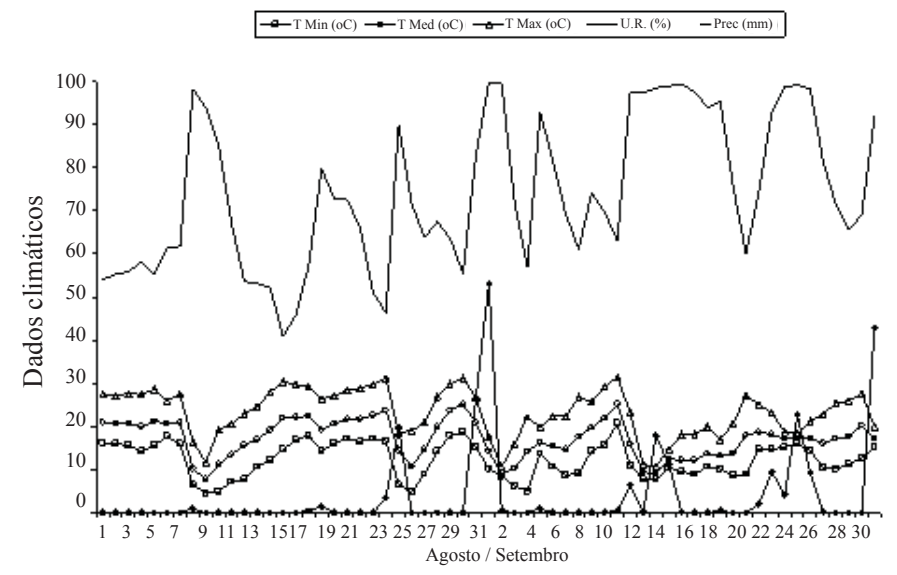

FIGURA 2. Dados de temperatura mínima, média e máxima $\left({ }^{\circ} \mathrm{C}\right)$, umidade relativa $(\%)$ e precipitação $(\mathrm{mm})$, nos meses de formação de sementes julho e agosto em Cascavel, 2005.

Após a debulha das espigas, as sementes foram submetidas ao teste de germinação, com quatro repetições de 100 sementes, a $28^{\circ} \mathrm{C} \pm 1^{\circ} \mathrm{C}$. As sementes de uma das amostras destinadas à avaliação da germinação foram previamente submetidas ao pré-esfriamento, para a superação da dormência, em câmara tipo B.O.D., a $6^{\circ} \mathrm{C} \pm 1^{\circ} \mathrm{C}$, durante cinco dias (Brasil, 1992). Outra amostra de sementes, representando a testemunha, foi submetida ao teste de germinação sem pré-esfriamento.

A contagem de plântulas normais, anormais e de sementes mortas e dormentes, foi realizada cinco dias após a instalação do teste (Figura 3). As sementes que não germinaram foram reunidas e submetidas ao teste de tetrazólio para confirmar a presença de dormência, com quatro repetições de 50 sementes. Nesse teste, as sementes foram colocadas, entre as folhas de papel-toalha umedecidos, durante a noite e, no dia seguinte, seccionadas longitudinalmente. A melhor parte para visualizar o embrião de cada semente, foi imersa em uma solução $0,1 \%$ de tetrazólio (cloreto de 2,3,5-trifenil tetrazólio), durante duas horas, no escuro, em câmara de germinação do tipo B.O.D., a $35^{\circ} \mathrm{C}$ (Brasil, 1976). Após o tratamento as sementes foram lavadas em água corrente para determinar as sementes viáveis e as mortas.
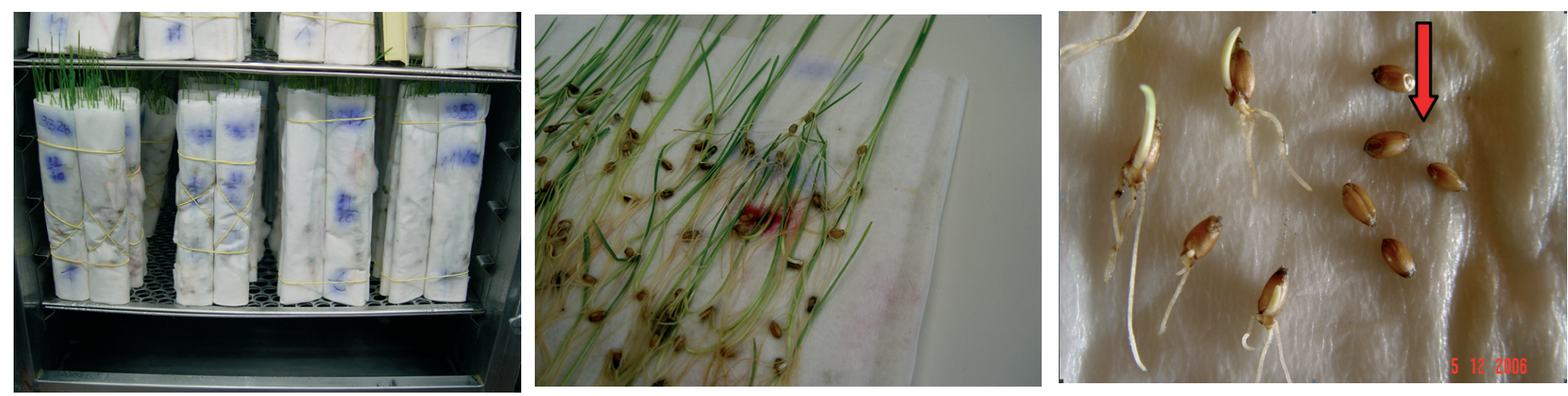

FIGURA 3. Rolos de papel toalha com sementes germinadas (A), plântulas normais (B) e presença de sementes dormentes (C) no teste de germinação.

Os dados foram submetidos ao teste de Shapiro-Wilk (Shapiro e Wilk, 1965), para verificação da normalidade dos erros. A seguir, a homogeneidade das variâncias foi avaliada pelo teste de Levene (Levene, 1960). Posteriormente à análise de variância, foi empregado o teste de WallerDuncan $(\mathrm{p}<0,05)$ para a comparação entre as médias dos tratamentos (Waller e Duncan, 1969; 1972).

\section{RESULTADOS E DISCUSSÃO}

Por meio do teste de germinação realizado em laboratório, com as sementes oriundas das espigas colhidas na localidade de Palotina, foi possível constatar que as cultivares Frontana e IAPAR 53 apresentaram menor porcentagem de germinação (Figura 4). As sementes das cultivares BRS 208, BRS 210, CD 104 e BRS 18 apresentaram maior porcentagem de germinação que as sementes de Ônix, Frontana e IAPAR 53; as de 'Ônix' superaram as de 'Frontana' e as de 'IAPAR 53'. A maior percentagem de germinação das sementes das cultivares avaliadas foi inferior a $90 \%$, sendo que, através deste teste, não foi possível obter a expressão do máximo percentual possível de germinação (100 \%) na maturidade fisiológica. 


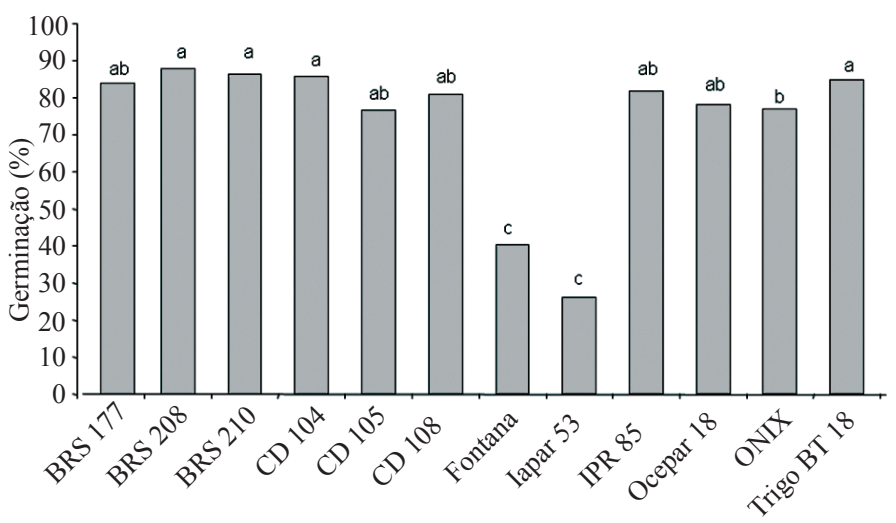

Cultivares de trigo

FIGURA 4. Percentagem de germinação de doze cultivares de trigo, colhidas no estádio de maturidade fisiológica, em Palotina-PR (2005). Colunas identificadas com a mesma letra não diferem entre si pelo teste de Waller-Duncan $(\mathbf{p}<\mathbf{0 , 0 5})$.

Os resultados de germinação para as cultivares Frontana e IAPAR 53 revelaram, também, o maior número de sementes dormentes (Figura 5), confirmada pelo teste de tetrazólio. É provável que as sementes tenham manifestado maior ocorrência de dormência porque, durante o enchimento de grãos não ocorreram chuvas e a temperatura média esteve próxima a $20^{\circ} \mathrm{C}$, condições consideradas favoráveis para a manifestação da dormência em sementes de trigo (Belderock, 1976; Reddy et al., 1985; Lunn et al., 2001; Castro et al., 2004). Assim, as cultivares com menor porcentagem de germinação podem ter atingido o pico máximo de dormência justamente nessa fase de maturidade.

À medida que as sementes se aproximam da maturidade fisiológica, há redução progressiva da atividade do ácido giberélico (GA) e de elevação dos níveis de ácido abscísico (ABA), responsável pela manifestação da dormência, caso as condições de ambiente permaneçam favoráveis à síntese desse inibidor (Taiz e Zeiger, 2004). Segundo Hilhorst (1995), a maior taxa de ABA é verificada quando as sementes atingem máxima massa seca, ainda muito úmidas, e decresce rapidamente à medida que progride a secagem, na fase final de maturação. Esta fase coincide com o período de desligamento das sementes da planta mãe, com subseqüente redução do grau de umidade da semente, e pode estar relacionada à alta concentração de $\mathrm{ABA}$, envolvido em processos de síntese e com ação de bloqueio da germinação.

O tratamento com baixa temperatura para a quebra da dormência não foi suficiente para as sementes das cultivares
Frontana e IAPAR 53 (Figura 6). Assim, sementes de 'Frontana' e de 'IAPAR 53' exibiram a maior porcentagem de sementes dormentes (Figura 7), provavelmente pela alta concentração de ABA (Taiz e Zeiger, 2004). Portanto, o préesfriamento não surtiu maior efeito na quebra de dormência dessas sementes.

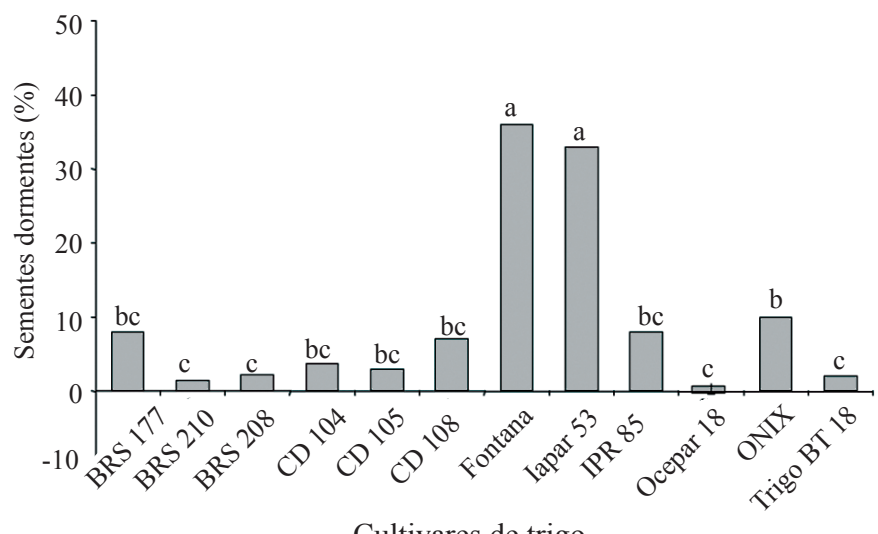

Cultivares de trigo

FIGURA 5. Percentagem de sementes dormentes detectadas no teste de tetrazólio, de doze cultivares de trigo, colhidas no estádio de maturidade fisiológica em Palotina-PR (2005). Colunas identificadas com a mesma letra não diferem entre si pelo teste de Waller-Duncan $(\mathbf{p}<\mathbf{0 , 0 5})$.

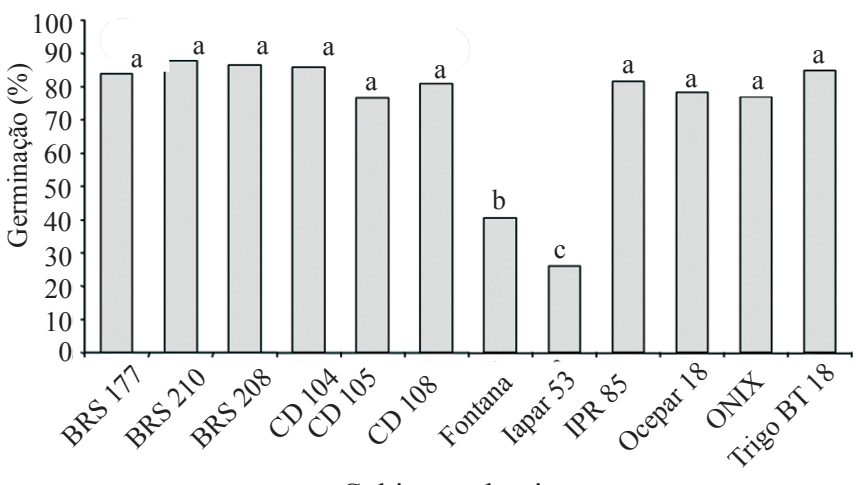

Cultivares de trigo

FIGURA 6. Percentagem de germinação, com superação de dormência por pré-esfriamento, de doze cultivares de trigo, colhidas no estádio de maturidade fisiológica em Palotina-PR (2005). Colunas identificadas com a mesma letra não diferem entre si pelo teste de Waller-Duncan $(\mathbf{p}<\mathbf{0 , 0 5})$. 


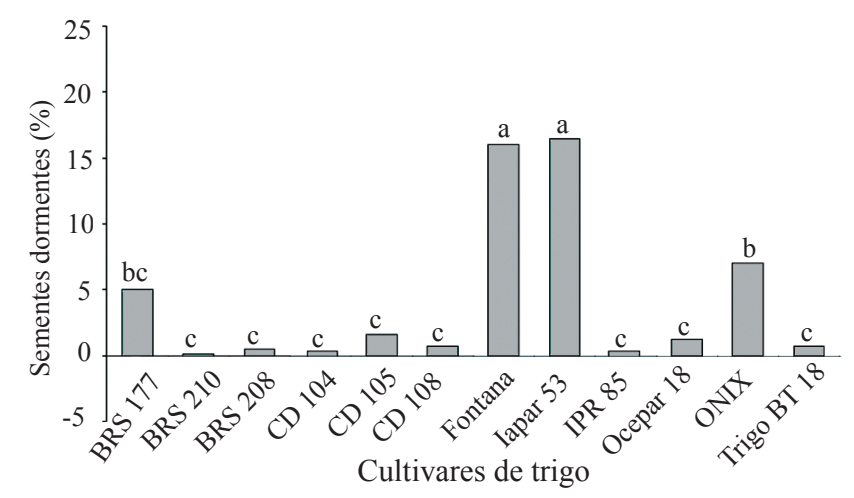

FIGURA 7. Percentagem de sementes dormentes no teste de tetrazólio, com superação de dormência por pré-esfriamento, de doze cultivares de trigo colhidos no estádio de maturidade fisiológica, em Palotina-PR (2005). Colunas identificadas com a mesma letra não diferem entre si pelo teste de Waller-Duncan $(p<0,05)$.

A maioria das cultivares avaliadas praticamente não apresentou sementes dormentes. Uma possível explicação para isto estaria na progressiva eliminação do mecanismo de dormência pelo melhoramento genético, ao longo de várias décadas. Os resultados aqui obtidos realçam a necessidade de reavaliar o processo de melhoramento, para que as fontes de dormência sejam exploradas com mais eficiência, visando aumentar a tolerância à germinação de sementes ainda presas à espiga.

Nos testes realizados com sementes colhidas em Cascavel, as cultivares Frontana e IAPAR 53 também apresentaram menor porcentagem de germinação (Figura 8), com valores inferiores à exigência mínima para a comercialização de sementes de trigo, ou seja, $80 \%$.

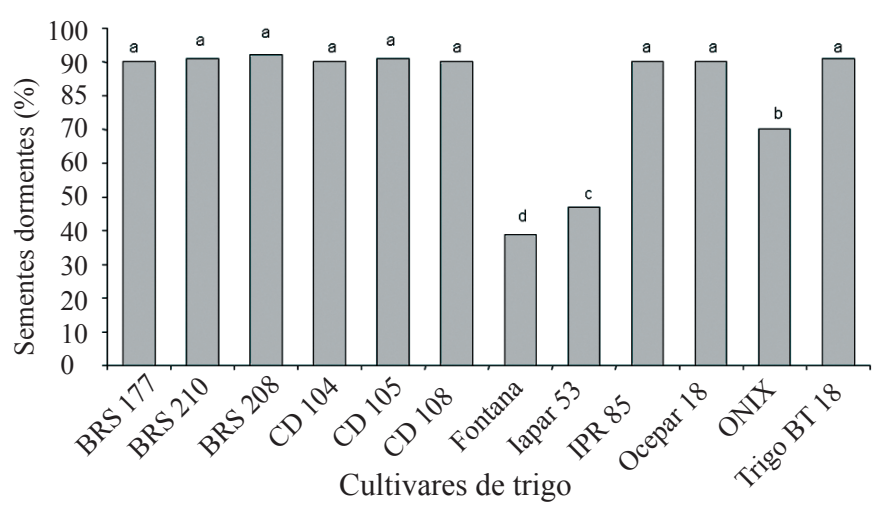

FIGURA 8. Percentagem de germinação de doze cultivares de trigo, colhidas em Cascavel-PR (2005). Colunas identificadas com a mesma letra não diferem entre si pelo teste de Waller-Duncan $(p<0,05)$.
Os dados de percentagem de sementes dormentes produzidas em Cascavel, confirmada no teste do tetrazólio, indicaram que as sementes de 'Frontana' e de 'IAPAR 53' exibiram níveis suficientemente expressivos de dormência, mantendo resistência apreciável à germinação. A expressão dessa dormência, na maioria das áreas tritícolas, teria impacto significativo nos trabalhos de melhoramento genético do trigo, pois o caráter poderia ser transferido à base genética de várias cultivares de interesse econômico.

A superação da dormência nas sementes colhidas em Cascavel permitiu a obtenção de germinação uniforme para todas as cultivares, dentro dos padrões estabelecidos para a comercialização de sementes (Figura 9). Esses resultados comprovam que o procedimento laboratorial adotado para a superação da dormência foi adequado e indica que as condições ambientais em Cascavel devem ter favorecido a superação da dormência das sementes, ao contrário do verificado em Palotina.

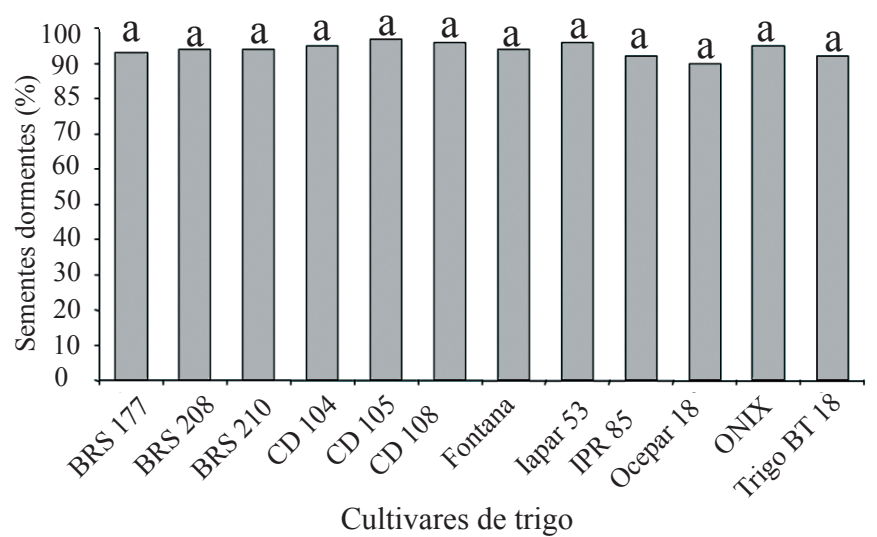

FIGURA 9. Percentagem de germinação, com superação de dormência, de doze cultivares de trigo colhidas no estádio de maturidade fisiológica, em Cascavel-PR (2005). Colunas identificadas com a mesma letra não diferem entre si pelo teste de Waller-Duncan (p>0,05).

As cultivares Frontana e IAPAR 53 revelaram uma baixa porcentagem de sementes germinadas, possivelmente pela ação do ABA. O resultado não surpreende porque Frontana é considerada como a principal base genética da tolerância à germinação de sementes ainda presas à espiga, do germoplasma nacional (Linhares, 1979; Reis e Carvalho, 
1989; Rosa, 1999; Tonon, 2001; Bassoi, 2002). Os trabalhos desenvolvidos para a avaliação da tolerância à germinação na espiga (Linhares, 1979; Reis e Carvalho, 1989; Rosa, 1999; Tonon, 2001; Bassoi, 2002 e 2004) foram consistentes quando detectaram baixa germinação na cultivar Frontana. Este genótipo provavelmente apresenta um mecanismo de dormência que garante a resistência, mesmo sendo submetido a condições extremamente favoráveis à germinação. A cultivar IAPAR 53 descende de cruzamento com 'Sulino', uma cultivar derivada de 'Frontana'. Assim, é possível que os mesmos genes de Frontana estejam interferindo na baixa resposta à germinação verificada em IAPAR 53 .

O conhecimento dos fatores que interferem na tolerância de sementes maduras à germinação enquanto ainda presas à espiga, poderá auxiliar na definição do potencial de aceitação de cada cultivar. Um esquema de melhoramento genético que possibilite a transferência da dormência para novas cultivares, de modo a impedir a germinação das sementes antes da colheita, pode possibilitar obtenção de maiores rendimentos e garantir um produto com os padrões desejados pela indústria.

\section{CONCLUSÕES}

O teste de pré-esfriamento aplicado a sementes de trigo, obtidas em ambientes favoráveis a expressão de dormência, pode não ser eficiente para superá-la, sendo fundamental a continuidade da pesquisa para identificação segura de fatores que possam induzir à manifestação desse fenômeno e o controle da germinação de sementes ainda presas à espiga a partir da época da maturidade fisiológica.

A dormência de sementes, detectada em 'Frontana' e 'IAPAR 53', pode representar uma importante base genética para ser explorada pelos programas de melhoramento, procurando contribuir para o incremento da tolerância a germinação das sementes ainda presas a espiga.

\section{REFERÊNCIAS}

BARNARD, A.; DEVENTER, C.; MAARTENS, H. Genetic variability of preharvest sprouting - the South African situation. Euphytica, v.143, n.3, p.291-296, 2005.

BASSOI, M.C. Quantitative trait analysis of grain dormancy in wheat (Triticum aestivum L. Thell). 2002. $240 \mathrm{f}$. Thesis (Ph.D. in Biotechnology Plant Breeding) - John Inns Centre \& University of East Anglia, Norwich, UK.

BASSOI, M.C. Introdução ao problema da germinação pré- colheita em trigo no Brasil. In: CUNHA, G.R.; PIRES, J.L.F. (Ed.). Germinação pré-colheita em trigo. Passo Fundo, 2004. p.21-136.

BELDEROK, B. Changes in the seed coat of wheat kernels during dormancy and after-ripening. Cereal Research Communications, v.4, p.165-171, 1976.

BEWLEY, J.D.; BLACK, M. Seed: physiology of development and germination. New York, Plenum Press, 1985. 367p.

BRASIL. Ministério da Agricultura e Reforma Agrária. Regras para análise de sementes. Brasília, DF: SNAD/ DNDV/CLAV, 1992. 365p.

BRASIL. Ministério da Agricultura e Reforma Agrária. Manual do teste de tetrazólio em sementes. Brasília, DF: AGIPLAN, 1976. 85p.

CARVALHO, N.M.; NAKAGAWA, J. Sementes: ciência, tecnologia e produção. 4.ed. Jaboticabal: FUNEP, 2000. $588 \mathrm{p}$.

CASTRO, R.D.; BRADFORD, K.J.; HILHORST, H.W.M. Embebição e reativação do metabolismo. In: FERREIRA, A.G.; BORGHETTI, F. (Orgs.). Germinação do básico ao aplicado. Porto Alegre, 2004. p.149-162.

CUNHA, G.R.; PIRES, J.L.F.; PASINATO, A. Introdução ao problema da germinação na pré-colheita em trigo no Brasil. In: CUNHA, G.R.; PIRES, J.L.F. (Ed.). Germinação pré-colheita em trigo. Passo Fundo, 2004. p.11-20.

DERERA, N.F. The audit of sprouting. Cereal Research Communications, v.8, p.15-22, 1980.

FLINTHAM, J.E. Different genetic components control coat-imposed and embryo-imposed dormancy in wheat. Seed Science Research, v.10, p.43-50, 2000.

FLINTHAM, J.E.; GALE, M.D. Dormancy gene maps in homoeologous cereal genomes. In: INTERNATIONAL SYMPOSIUM ON PRE-HARVEST SPROUTING IN CEREALS, 7., 1996, Abashiri-shi. Proceedings... Abashirishi: Center for Academic Societies, 1996. p.143-149. Edited by K. Noda, D.J. Mares

HAGEMANN, M.G.; CIHA, A.J. Environmental x genotype effects on seed dormancy and after-ripening in wheat. Agronomy Journal, v.79, p.192-196, 1987.

HANFT, J.M.; WYCH, R.D. Visual indicators of physiological maturity in hard red spring wheat. Crop Science, v.22, p.584-587, 1982.

HILHORST, H.W.M. A critical update on seed dormancy. I. Primary dormancy. Seed Science Research, v.5, p.1-73, 
1995.

INFORMAÇÕES técnicas para as culturas do trigo e triticale no Paraná 2003. Londrina: IAPAR, 2003. 202p. (IAPAR. Circular, 126)

KHAN, A.A. Cytokinins: permissive role in seed germination. Science, v.171, p.853-859, 1971.

KIGEL, J.; GALILI, G. Seed development and germination. New York, 1995. 491p.

KING, R.W. Manipulation of grain dormancy in wheat. Journal of Experimental Botany, v.44, p.1059-1066, 1993.

LEVENE, H. Robust tests for equality of variances. In: OLKIN, I. (Ed). Contributions to probability and statistics. Palo Alto: Stanford University Press, 1960. p.278-292.

LINHARES, A.G. Germinação da semente na espiga em trigo. Revista Brasileira de Sementes, v.1, n.3, p.25-28, 1979.

LUNN, G.D.; MAJOR, B.J.; KETTLEWELL, P.S.; SCOTT, R.K. Mechanisms leading to excess alpha-amylase activity in wheat (Triticum aestivum, L.) grain in the U.K. Journal of Cereal Science, v.33, p.313-329, 2001.

MIURA, H.; SATO, N.; KATO, K.; AMANO, Y. Detection of chromosomes carrying genes for seed dormancy of wheat using the backcross reciprocal monosomic method. Plant Breeding, v.121, p.394-399, 2002.

OSA, M; KATO, K.; MORI, M.; SHINDO, C.; TORADA, A.; MIURA, H. Mapping QTLs for seed dormancy and the $\mathrm{Vp} 1$ homologueon chromosome $3 \mathrm{~A}$ in wheat. Theoretical and Applied Genetics, v.106, p.1491-1496, 2003.

POPINIGIS, F. Fisiologia da semente. Brasília, DF: AGIPLAN, 1985. 289p.
REDDY, L.V.; METZGER, R.J.; CHING, T.M. Effect of temperature on seed dormancy of wheat. Crop Science, v.25, p.455-458, 1985.

REIS, M.S.; CARVALHO, F.I.F. Eficiência de três métodos artificiais para identificação da variabilidade do caráter germinação na espiga em trigo. Revista Brasileira de Fisiologia Vegetal, v.1, n.1, p.63-72, 1989.

ROSA, A.C. Pre-harvest sprouting tolerance of a synthetic hexaploid wheat (Triticum turgidum L. $\mathrm{x}$ Aegilops tauschii Coss.). 1999. 69 f. Dissertação (Mestrado) - Oregon State University, Corvallis.

SHAPIRO, S.S.; WILK, M.B. An analysis of variance test for normality. Biometrika, v.52, n.3, p. 591-599, 1965.

SIMPSON, G.M. Seed dormancy in grasses. Cambridge, New York. 1990. 296p.

SVENSSON, F. Screening methods for sprouting resistance in wheat. Cereal Research Communications, v.4, n.2, p.263-266, 1976.

TAIZ, L.; ZEIGER, E. Fisiologia vegetal. 3. ed. Porto Alegre: Artmed, 2000. 719p.

TONON, V.D. Genética da resistência à germinação na espiga em trigo. 2001. 63 f. Dissertação (Mestrado) Programa de pós-graduação em Fitotecnia, Faculdade de Agronomia, Universidade Federal do Rio Grande do Sul, Porto Alegre.

WALLER, R.A.; DUNCAN, D.B. A Bayes rule for the symmetric multiple comparison problem. Journal of the American Statistical Association, v.64, p.1484 -1499, 1969.

WALLER, R.A.; DUNCAN, D.B. Corrigenda. Journal of the American Statistical Association, v. 67, p.253 -255, 1972. 